\title{
Characterizing the impact of climatic and price anomalies on agrosystems in the northwest United States
}

\author{
Patrick Wurster ${ }^{\mathrm{a}, *}$, Marco Maneta $^{\mathrm{a}}$, Santiago Beguería ${ }^{\mathrm{c}}$, Kelly Cobourn ${ }^{\mathrm{f}}$, Bruce Maxwell ${ }^{\mathrm{e}}$, \\ Nick Silverman $^{\mathrm{d}}$, Stephanie Ewing ${ }^{\mathrm{e}}$, Kelsey Jensco ${ }^{\mathrm{d}}$, Payton Gardner ${ }^{\mathrm{a}}$, John Kimball ${ }^{\mathrm{g}}$, \\ Zachary Holden $^{\mathrm{b}}$, Xinde $\mathrm{Ji}^{\mathrm{f}}$, Sergio M. Vicente-Serrano ${ }^{\mathrm{h}}$ \\ ${ }^{\text {a }}$ Geosciences Department, University of Montana, Missoula, Montana, USA \\ ${ }^{\mathrm{b}}$ U.S. Forest Service, Missoula, Montana, USA \\ ${ }^{\mathrm{c}}$ Estación Experimental de Aula Dei, Consejo Superior de Investigaciones Científicas (EEAD-CSIC), Zaragoza, Spain \\ ${ }^{\mathrm{d}}$ WA Franke College of Forestry \& Conservation, University of Montana, Missoula, Montana, USA \\ ${ }^{\mathrm{e}}$ Land Resources and Environmental Sciences, Montana State University, Bozeman, Montana, USA \\ ${ }_{\mathrm{f}}^{\mathrm{f}}$ Department of Forest Resources and Environmental Conservation, Virginia Tech, Blacksburg, Virginia, USA \\ ${ }^{\mathrm{g}}$ Numerical Terradynamic Simulation Group, University of Montana, Missoula, Montana, USA \\ ${ }^{\mathrm{h}}$ Instituto Pirenaico de Ecología, Consejo Superior de Investigaciones Científicas (IPE-CSIC), Zaragoza, Spain
}

\section{A R T I C L E I N F O}

\section{Keywords:}

Agriculture

Climatic anomalies

Crop production

Drought

Standardized precipitation index (SPI)

Evaporative Demand Drought Index (EDDI)

\begin{abstract}
A B S T R A C T
We present an analysis of the sensitivity of three key crops (alfalfa, barley and winter wheat) produced in the northwestern United States to climatic and agricultural market anomalies using widely used standardized indices. Rather than investigating sensitivity of crop yields (production per unit area), we focus on agricultural production (yield * harvested area) anomalies, which captures both variations in yield and the effect of decisionmaking factors such as allocation of cropping area. We used two well-known standardized precipitation and reference evapotranspiration (ETo) indices (SPI and EDDI, respectively) and a standardized crop value index in a multivariate linear regression analysis to determine the characteristic timing and time-scales of precipitation and ETo anomalies that best explain annual crop production anomalies. Since climatic and market factors are standardized, regression coefficients are interpreted as a sensitivity measure that captures the relative effect of climatic and agricultural markets on agricultural production. Results show that alfalfa production was most sensitive climatic anomalies while barley and wheat production was more responsive to crop prices. Sensitivity to precipitation anomalies followed gradients in precipitation, temperature, and soil moisture regimes across the study area where drier and warmer climates were associated with increased sensitivity to climatic anomalies. We found that irrigation decoupled alfalfa production from climatic variability, but the effect of irrigation on decoupling barley production was less clear. Winter wheat production was most sensitive to price anomalies, and alfalfa was least sensitive. Omitting agricultural market conditions and other farmer incentives may introduce biases in our understanding of how drought and climate change impact agricultural production.
\end{abstract}

\section{Introduction}

Climate variability in agricultural regions affects soil moisture and available energy (Salinger et al., 2000), increasing the risk farmers take when they make resource-use decisions such as how much land they allocate to the crops they choose to grow and where to distribute scarce irrigation water. Farmer's perception of risk affects this decisionmaking, with potential consequences for regional agricultural production (yield * harvested area) and food security (Lawrence et al., 2018). Concerns about rural well-being, economic development and food security have led to an increasing number of studies investigating the sensitivity of crop yield (production per unit area) and production to climate variability with concentration on drought (Iizumi and Ramankutty, 2015a; Lobell and Asner, 2003; Lobell and Field, 2007; Peña-Gallardo et al., 2018b). From the many environmental stresses that affect crop production (e.g., soil salinity, frost, soil erosion), drought is one of the most prevalent (Porter and Semenov, 2005; Shao et al., 2009). In terms of agriculture, crop sensitivity to the different constituents of drought varies by cultivation and over the growth cycle of a given crop. Cereal crops, for example, may experience reduced

\footnotetext{
* Corresponding author.

E-mail address: pmwurster@gmail.com (P. Wurster).
} 
productivity due to unusually high temperatures during the grain filling period, even though precipitation deficits are not present (Lobell et al., 2012). Alternatively, unusually high temperatures at the beginning of the growing season may increase cereal crop productivity by allowing for earlier sowing dates (Lanning et al., 2010).

Several drought indices based upon meteorology have been developed specifically for agriculture (Heim, 2002; Mukherjee et al., 2018). The most widely used climate index is the Palmer Drought Severity Index (PDSI), based upon precipitation, temperature, available soil water, runoff, and atmospheric water demand (Palmer, 1965). McKee et al. (1993) developed the Standardized Precipitation Index (SPI), which provides a definition of drought severity accumulated over different time-scales using precipitation alone. Hobbins et al. (2016) developed the Evaporative Demand Drought Index (EDDI) which provides a definition of drought severity accumulated over different time-scales based on potential evapotranspiration. Vicente-Serrano et al. (2010) developed the Standardized Precipitation Evapotranspiration Index (SPEI) to describe drought conditions accumulated over different timescales based on precipitation and the atmospheric evaporative demand. An alternative index that captures drought from the point of view of the atmospheric demand is the Standardized Evapotranspiration Deficit Index (SEDI), which uses the difference between potential and actual evapotranspiration to describe drought conditions (Kim and Rhee, 2016; Vicente-Serrano et al., 2018). Drought indices with the ability to capture drought conditions accumulated over different time-scales have been shown to perform better for predicting crop production or yields than traditional 'static' indices such as the PDSI (Peña-Gallardo et al., 2018a; Vicente-Serrano et al., 2012).

Most meteorology based indices used to characterize agricultural drought focus on the impact of climate factors on agricultural yields. However, to investigate drought impacts on land use, on rural livelihoods and on food security it is better to focus on total production because growers can compensate for yield reductions and maintain profitability by increasing the planted area. Total crop production is an important metric that captures both the efficacy of agricultural practices and the impact of climate conditions, as well as the response of farmers in terms of land allocated to particular crops based on their perception of risk and the impact of other external factors such as agricultural markets and policy incentives (Iizumi and Ramankutty, 2015b). Therefore, while crop yield alone is certainly an important component of annual crop production, focusing on yields alone fails to capture farmer response and the compensatory effects that the reallocation of land may have on total food production. This may contribute to an overemphasis on the role of climate variability for food security.

Farmers are not only sensitive to climate conditions but also react to other factors such as crop prices and may choose to allocate resources to maintain agricultural production even under more adverse climate if market conditions are favorable or were favorable the previous year. Therefore, crop price should also be considered in crop production models (Lobell et al., 2011). Throughout this paper, we refer to the prices the farmer receives for their produce (farmgate prices) as crop price. Crop price can impact both crop yield and crop production in complex ways, and the two are not always directly related (Miao et al., 2016). Higher crop prices could reasonably be associated with monoculture of a better returning crop, which would increase production but has been associated with decreased yields over the long term (Hennessy, 2006). Alternatively, higher crop price for a given crop may encourage different crop rotations to improve soil quality, which would be associated with lower productivity but greater yields in the long term (Hennessy, 2006). The expectation of higher crop price may also result in a greater allocation of inputs (i.e., fertilizer, higher quality seed, pest management, etc.) accompanied by an increase in cropping area that contribute to increases in both yield and production. Therefore, although the expectation may be that crop prices mostly affect land allocation, it likely plays an important role in inter-annual variability of both crop yield and crop production.

This study investigates annual crop production anomalies in relation to three factors: precipitation anomalies (atmospheric supply anomalies), reference evapotranspiration (ETo) anomalies (atmospheric demand anomalies), and anomalies in the price that farmers receive for their crops the year prior to production. We focus on the northern region of the USA, which is an important wheat, barley and alfalfa producer and is representative of the agriculture of the US Northern Great Plains and US Rocky Mountain front. The objectives of this study were threefold: 1) Quantify the sensitivity of alfalfa, barley, and winter wheat production to precipitation, ETo and to price anomalies (as represented by SPI, EDDI and a standardized crop value index) at the county scale; 2) Compare production sensitivities to these anomalies between crops; 3) Cluster (i.e., group) counties based on spatial patterns of sensitivities of annual crop production to precipitation, ETo, and price and identify the regions most vulnerable to drought conditions.

\section{Methods}

\subsection{Study area}

The study focused on crop production anomalies in Idaho, Montana, North Dakota, South Dakota, and Wyoming, all located in the inland northwest of the US (Fig. 1a). The study region encompasses the portions of the intermountain west and the northern great plains region, and includes significant longitudinal physiographic and climate gradients associated with proximity to the Pacific Ocean and Gulf of Mexico (Salley et al., 2016). Topography further enhances climate gradients through orographic effects, where Idaho, western Montana, and western Wyoming are mountainous areas associated with the northern Rocky Mountain region, while eastern Montana, South Dakota, North Dakota, and eastern Wyoming are flat prairies associated with the Northern Great Plains (Fig. 1b). Generally, a precipitation gradient exists moving west to east, with some areas in Idaho receiving an average of $1000 \mathrm{~mm} / \mathrm{yr}$ of precipitation, and some areas in Wyoming and South Dakota receiving $<200 \mathrm{~mm} / \mathrm{yr}$ (Fig. 1c). Rain-fed production of the three crops within the study area was limited to areas receiving at least $300 \mathrm{~mm}$ of average annual precipitation over the study period, and primarily irrigated production starts in areas receiving at least $200 \mathrm{~mm} / \mathrm{yr}$. Temperature generally follows a similar gradient, with cooler temperatures in the Rocky Mountains and warmer temperatures in the Northern Great Plains (Fig. 1d).

Agricultural crop production is a key industry within the study area, however five or six major crops dominate total area under production. Three of these major crops, alfalfa, barley, and winter wheat, were chosen due to adequate period record and economic significance in the region, and because they are commonly produced across the study area. States in the study area are important contributors to the national production of these three crops. Idaho, Montana, and South Dakota were ranked second, third, and fourth in US alfalfa production, respectively, between 2015 and 2017 (USDA NASS). Idaho, North Dakota, Montana, and Wyoming ranked first, second, third, and fifth in the US for barley production. Montana and Idaho ranked sixth and seventh in the US for winter wheat production between 2015 and 2017 (USDA NASS). Farmers in Idaho, western Montana, and western Wyoming benefit from widespread irrigation infrastructure, while crop production in eastern Montana, North Dakota, South Dakota, and eastern Wyoming is primarily rain-fed (USDA NASS).

\subsection{Data analysis and preprocessing}

To investigate the response of anomalies in the annual crop production of alfalfa, barley, and winter wheat to anomalies in precipitation, ETo and crop price we used survey data for the period of 1979-2016. Crop production and crop price data were obtained from 


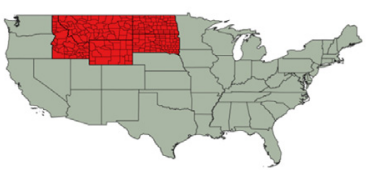

(a)

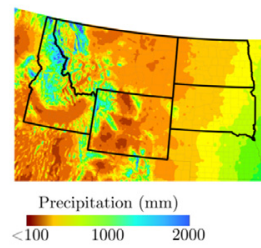

(c)

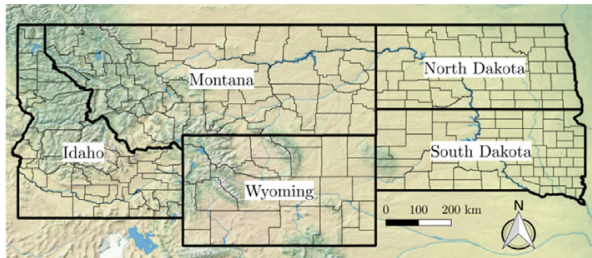

(b)

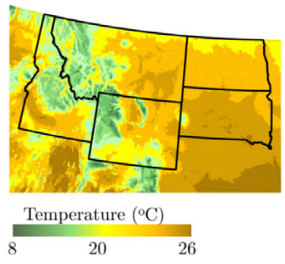

(d)

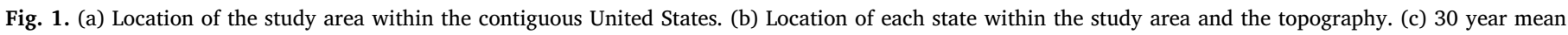
annual precipitation from 1979-2010 (Daly et al., 2008). (d) 30 year mean July temperature from 1981-2010 (Daly et al., 2008).

the US Department of Agriculture National Agricultural Statistics Service (USDA NASS). Production data is available at the county scale, while information on price received is available for each crop at the state scale. We only included counties in our analysis with at least 20 years of record. We also retrieved the annual irrigated production of each crop when available in the USDA NASS survey. We used the ratio of total irrigated production of a given crop to the total production of that crop over the study period in each county as a metric of the prevalence of irrigation in each county. Counties with $<40 \%$ irrigated total production were considered primarily rain-fed and counties with $>60 \%$ irrigated total crop production was classified as primarily irrigated. Counties with between $40 \%$ and $60 \%$ total irrigated production were not used in the comparison of sensitivity to precipitation and ETo between rain-fed and irrigated counties.

Gridded precipitation and ETo data were obtained from the University of Idaho Gridded Surface Meteorological Dataset, METDATA. This dataset uses information from the PRISM (Parameter elevation Relationships on Independent Slopes Model) (Daly et al., 2008) and the NLDAS-2 (NASA Land Data Assimilation System version2 (Mitchell, 2004) to generate a downscaled daily meteorological dataset at $4 \mathrm{~km}$ resolution for the continental US Abatzoglou (2013). The ETo grids included in METDATA are calculated using the American Society of Civil Engineering Penman-Monteith formulation with downscaled minimum and maximum temperature, vapor pressure deficit, wind speed, and downward shortwave radiation. Precipitation and ETo data were spatially averaged to the county scale and then temporally averaged to monthly time steps. Meteorological, price and agricultural production time series for each county were detrended using linear regression prior to the calculation of anomalies (S-1 through S-4).

Precipitation anomalies were described using the Standardized Precipitation Index (SPI), which characterizes drought by accumulating standardized anomalies over prescribed time-scales (McKee et al., 1993). We calculated 15 SPI time series for each county from monthly detrended precipitation information across the growing season (beginning in March and ending in September) using SPI timescales from 1 to 15 months. The SPI was fitted using a gamma distribution (VicenteSerrano et al., 2010). Precipitation anomalies (SPI) are hence referred to as precipitation.

ETo anomalies were described using the Evaporative Demand Drought Index (EDDI) (Hobbins et al., 2016). Like the SPI, EDDI characterizes drought over user defined timescales of accumulated anomalies. In this study we calculated EDDI over different time-scales using the empirical probability of ranked ETo values summed across the time-scales of interest (Hobbins et al., 2016), and then used inverse normal approximation described by Vicente-Serrano et al. (2010). We again developed 15 EDDI time series for each county across the growing season using 1 to 15 months EDDI time-scales from detrended historic ETo data. ETo anomalies are hence referred to as just ETo.

To calculate the time series of production and price anomalies, we followed the same methodology of the SPI calculations but on detrended time series of annual production for each county and crop, and of annual crop price for each state and crop. The time series of crop prices was lagged one year to reflect the assumption that farmers react to prices received the previous year (Miao et al., 2016). Another alternative is to assume that farmers react to commodity price futures for the current production year, however one-year lagged prices and crop price futures are highly correlated and can be used interchangeably with limited impacts on the analysis (Miao et al., 2016). We found that the distribution of standardized time series of crop productions and prices were best fitted using a log- logistic distribution instead of the gamma distribution recommended for precipitation. We refer to the resulting index of production anomalies as the Standardized Crop Production Index (SCPI), and the index of lagged price anomalies as the Standardized Crop Value Index (SCVI). The SCPI and SCVI were calculated for each county with a time-scale of one year. Since crop prices are only available at the state scale, the SCVI is identical for the counties in each state. Annual crop production anomalies are hence referred to as just production, and price received anomalies are referred to as just price.

The use of different lags for the meteorological indices is essential because we do not know a priori the characteristic time-scale of climate anomalies to which crop production responds. Strong differences have been recorded in response to different drought time-scales in natural vegetation (Pasho et al., 2011; Vicente-Serrano et al., 2013) and crops (Peña-Gallardo et al., 2018; Zipper et al., 2016). Identifying the correct time-scale is important to determine the inertia of crop production to climate variability.

\subsection{Models}

We assume that the incremental response of production is described by a linear combination of climate and price anomalies. These are reduced-form models in the sense that they describe collinearity between precipitation or ETo, price, and production anomalies, but they do not describe the underlying mechanisms that generate production in those 
counties. The relationship between meteorological and production anomalies appears to be linear or at least not strongly nonlinear according to our data (S-5). Linear models have been used by other studies to relate different measures of production with climatological factors (Steduto et al., 2007; Vicente-Serrano et al., 2006).

Instead of building a linear model with the SPI, EDDI and SCVI as independent variables, we chose to develop two different linear models to describe annual production anomalies, one based on precipitation and price (SPI and SCVI) and another based on ETo and price (EDDI and SCVI). The motivation was to avoid issues related to the correlation between SPI and EDDI and to reduce the number of variables that needed to be estimated in the final models. A single multiple regression including SPI and EDDI would be possible using a regularization method such as LASSO or ridge regression to handle the collinearity between SPI and EDDI. However, previous analysis by our team found that LASSO regression will zero out the EDDI coefficient resulting in an equivalent model to Eq. (1). We also found in cross validation analysis that Ridge Regression produces unstable and biased coefficients very dependent on the amount of ridging applied. The linear models are:

$S C P I_{i, j}^{p}=\alpha_{i, j, m, k} S P I_{m, k, j}+\beta_{i, j}^{p} S C V I_{s, i}+\gamma_{i, j, m, k}^{p}$

$S C P I_{i, j}^{e}=\delta_{i, j, m, k} E D D I_{m, k, j}+\beta_{i, j}^{e} S C V I_{s, i}+\gamma_{i, j, m, k}^{e}$

where SCPI is the annual production anomaly, $\alpha$ is the fraction of precipitation anomaly that translates to the production anomaly, $\delta$ is the fraction of ETo that translates to production anomaly, $\beta$ is the fraction of price anomaly that translates to production anomaly, and $\gamma$ is the intercept, which absorbs the effect of errors and the effect of other factors not explicitly included in the model. Subscripts indicate that the variables change with crop, $i$; state. $s$; county, $j$; month, $m$; and SPI or EDDI time scale, $k$. The superscript $p$ or $e$ differentiate the coefficients for the precipitation model (Eq. (1)) or the ETo model (Eq. (2)).

We used a hierarchical linear regression (HLR) approach (Gelman et al., 2013; McMahon and Diez, 2007) to determine the model regression coefficients. We assumed t-distributed crop production data errors (Gelman et al., 2013, p. $435 \mathrm{ff}$ ) to increase robustness and reduce the risk that outliers in the crop production dataset could bias the inference of the coefficient values. We included as a calibration parameter the degrees of freedom of the t-distribution that control the tails of the distribution (i.e., $\nu$ shown in Fig. 2). To identify the optimal SPI and EDDI time-scales and the most sensitive month of the growing season for each county, we first ran a maximum likelihood method to determine prediction errors from Eq. (1) and (2) using each combination of time-scale and month of the growing season of the SPI and EDDI time series. For each combination of time-scale and month we recorded the root mean square error (RMSE) of the prediction and selected the timescale and month combination with the lowest RMSE for each county as the characteristic SPI or EDDI timescale and month. We then determined confidence intervals of the regression coefficients associated with the characteristic SPI and EDDI time series determined for each county by sampling the HLR model coefficients using a Markov chain Monte Carlo (MCMC) method.

A HLR method was employed to increase the regression robustness and augment the datasets with group level (state) information. In Bayesian HLR, a set of hyperparameters at the higher level (state level) are sampled from prescribed state-level distributions, which are subsequently used to inform the prior distribution of county-level regression parameters (Gelman et al., 2013). HLR also accommodated the fact that crop prices data also was only available at the state scale. A schematic of the MCMC robust hierarchical regression algorithm shown presented in Fig. 2. A common problem in hierarchical regression is that when the sampler of the group variance (upper level) is exploring regions close to zero, the sampling at the individual level (lower level) become very inefficient because the probability that the chain can take a long step and explore away from the group mean is small. To solve this we use a linear transform that uses values sampled from the standard normal distribution ( $\alpha^{\text {offsets, }, i, j}, \beta^{\text {offset }, i, j,}, \gamma^{\text {offsets,i,j }}$ in Fig. 2) to offset the hyperparameters away from the group means (for details see Betancourt and Girolami, 2015, p. 80ff). The HLR model was implemented in python using the pyMC3 library (Salvatier et al., 2015). The posterior distribution of county-scale regression coefficients sampled by the MCMC HLR was used to identify the $95 \%$ confidence intervals. Statistical analysis of coefficients was limited to only those determined to be significant at the $95 \%$ confidence interval $(p=0.05)$.

\subsection{Clustering analysis}

The different patterns of spatial variation of agricultural production to climatic and price drivers make it very difficult to visually identify regions exhibiting similar characteristics. We used a clustering analysis to establish groups of counties representing strong, average, and weak relationships between climate, crop price and production anomalies.

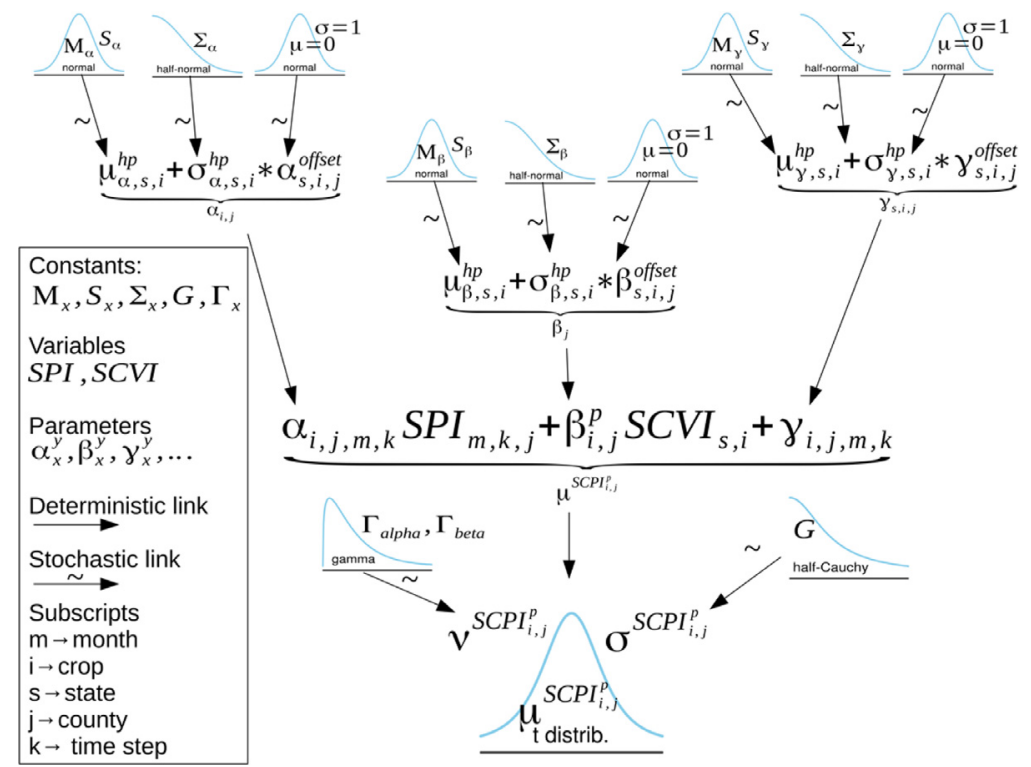

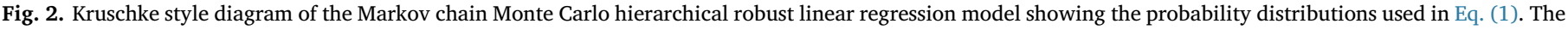
same model structure was used for Eq. (2), except the EDDI index was used as the independent climatic variable. 


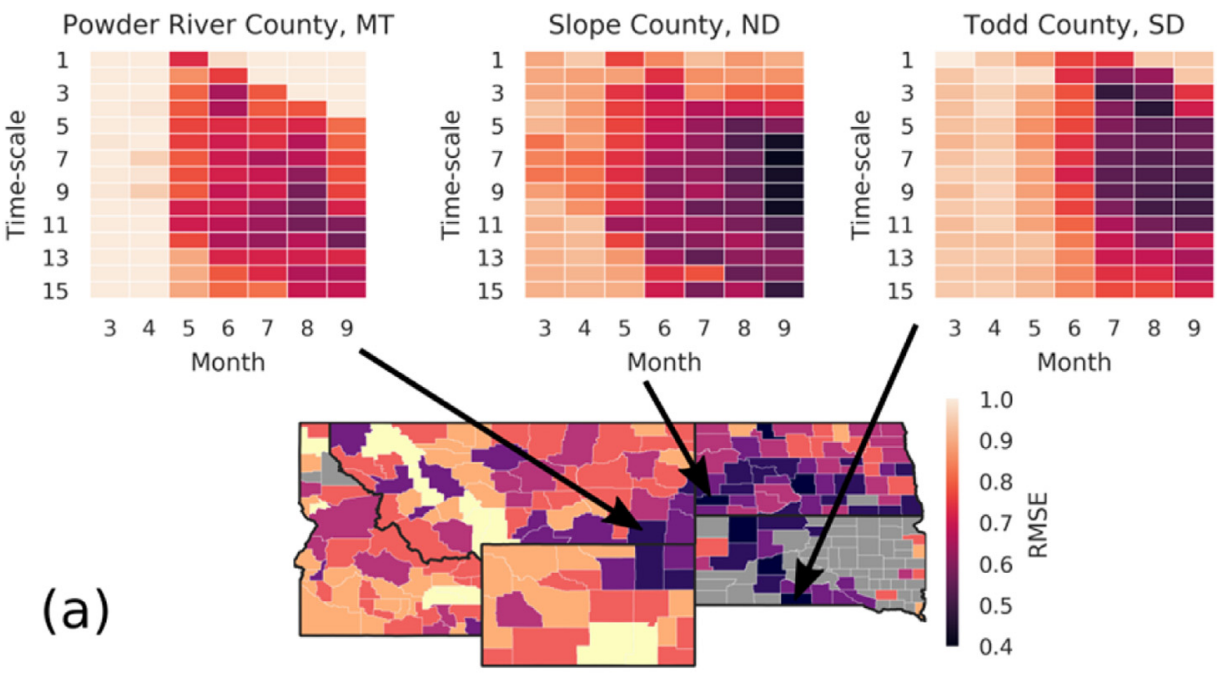

(b)
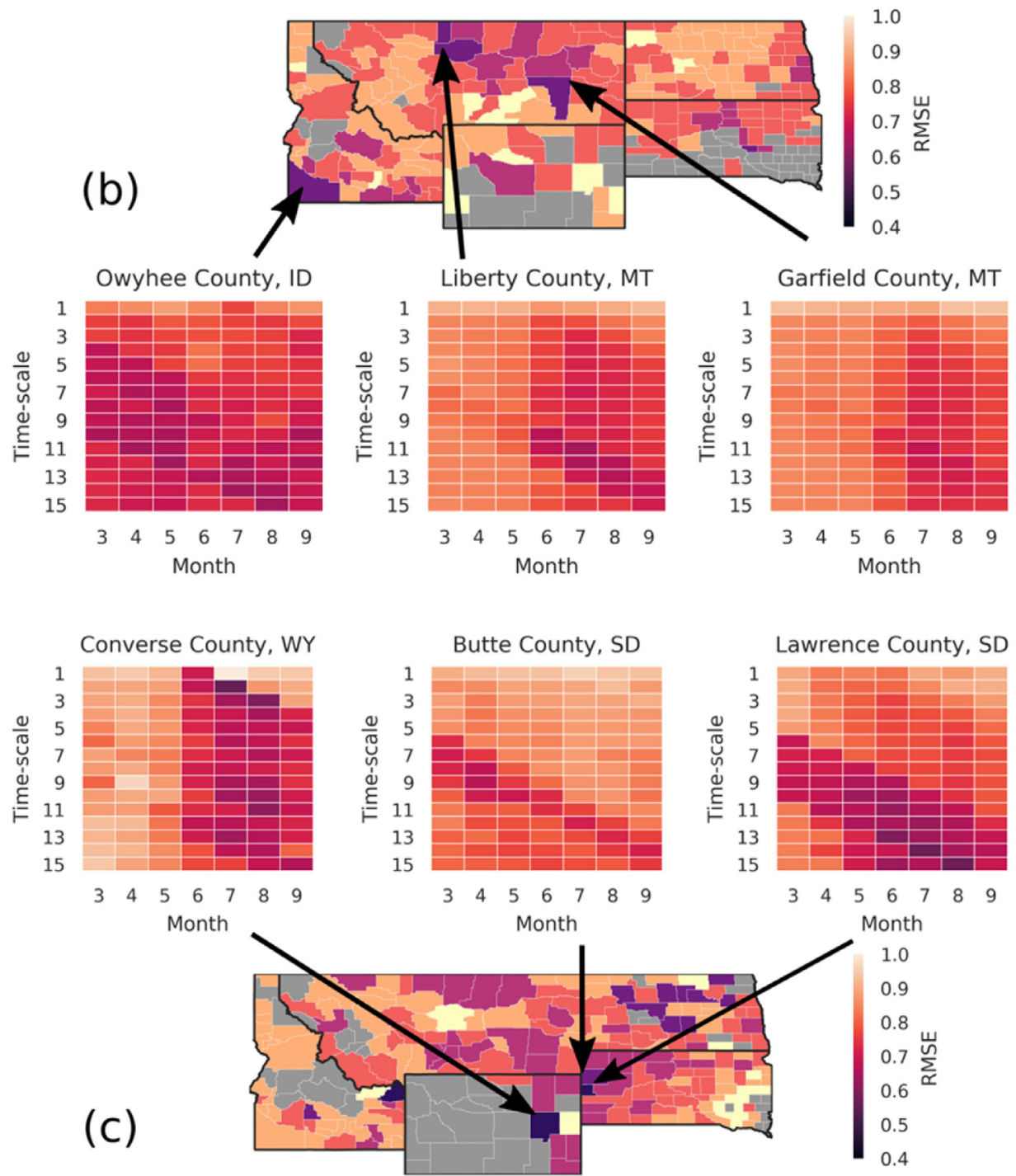

Fig. 3. RMSEs from the best time-scale and month combination for each county produced by the SPI-SCVI model (Eq. (1)) for alfalfa (a), barley (b) and winter wheat (c), along with examples of heat maps for a few selected counties illustrating the model performances for all combinations of considered monthly time-scales and months during the growing season. 

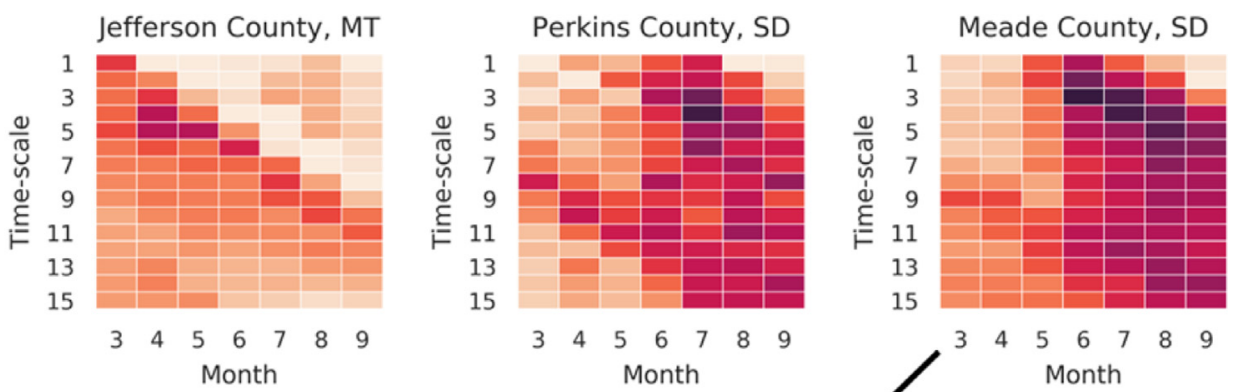

(a)

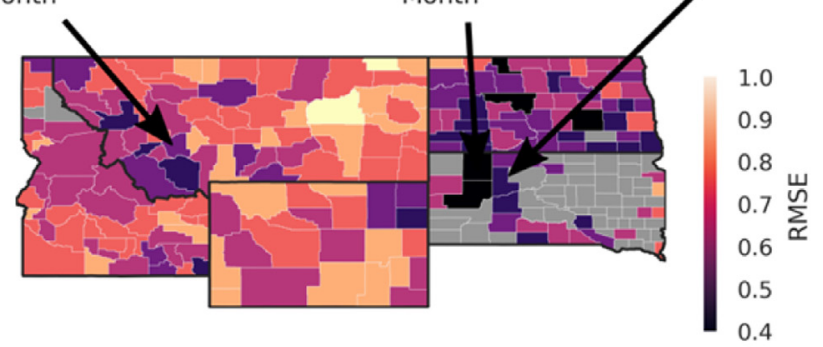

(b)
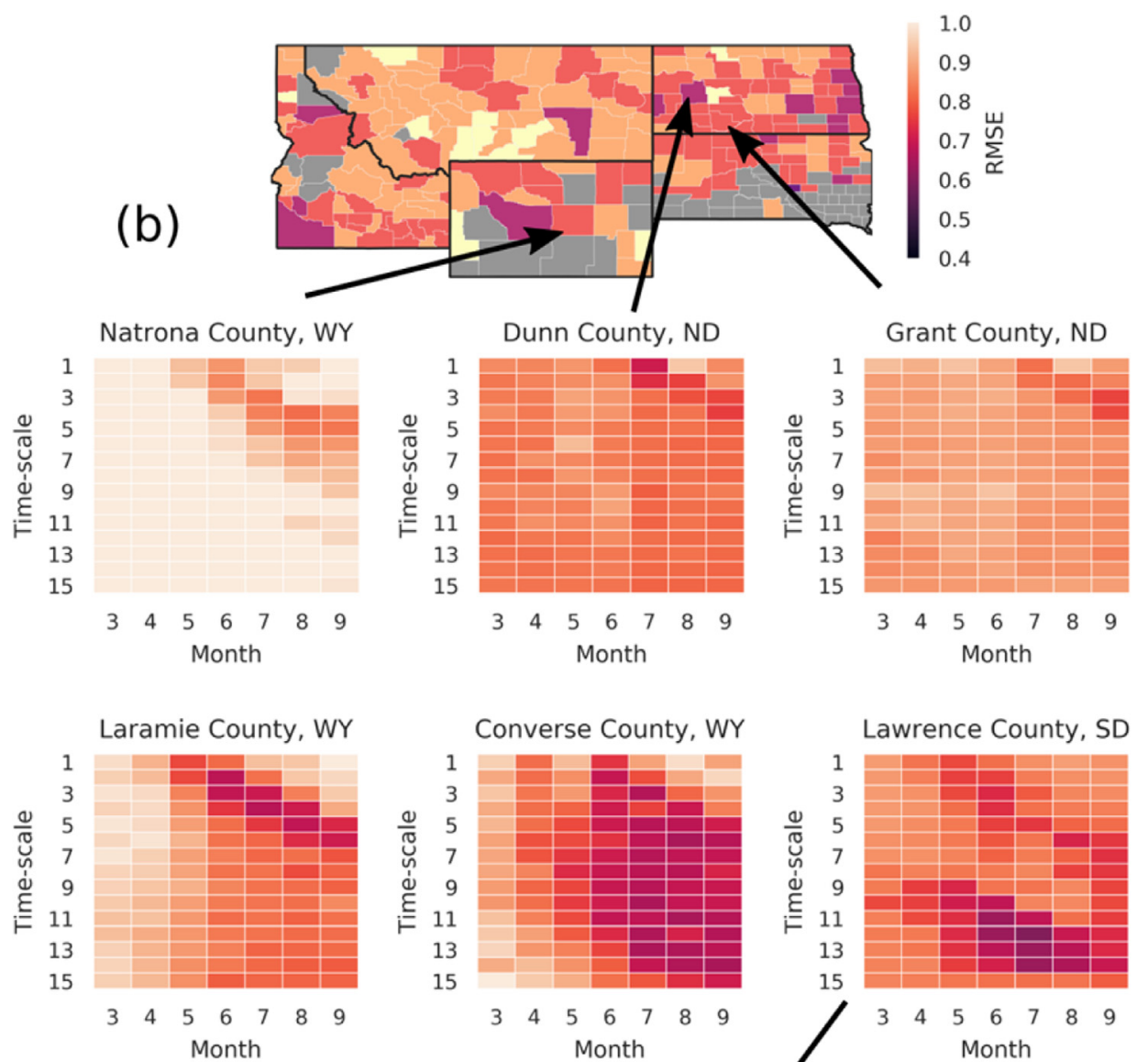

Lawrence County, SD

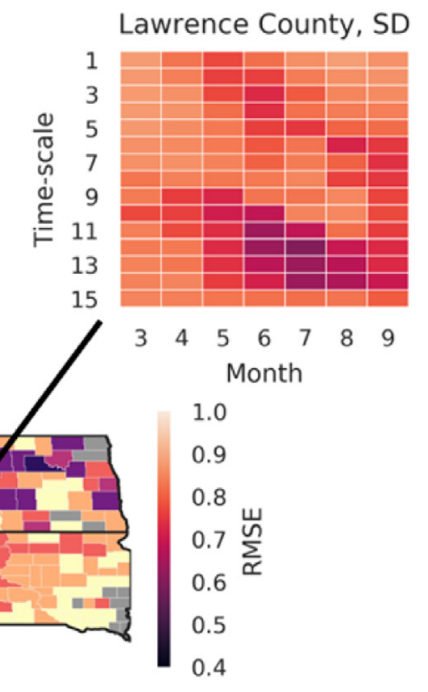

Fig. 4. Same as Fig. 3 but for the EDDI-SCVI model (Eq. (2)). 
This type of analysis allowed us to classify counties where annual crop production anomalies exhibited similar sensitivity to precipitation, ETo or price, revealing spatial patterns due to climatic or economic similarities.

We chose a K-means cluster analysis (Hartigan and Wong, 1979) to classify counties with similar crop production sensitivities to precipitation, ETo, and price for each crop under study as reflected in the mean of the model coefficient distribution approximated by the MCMC simulations. For the clustering analysis, all mean climatic and price coefficients were used, regardless of their significance. We determined an optimal number of 3 clusters using silhouette plots (Rousseeuw, 1987). Violin plots were used to display the mean and distribution of coefficients that characterize each cluster for each crop.

\section{Results}

\subsection{Response time-scale of crop production}

The characteristic climatic time-scale and the most sensitive month that best explained crop production anomalies varied per county and per crop. Figs. 3 and 4 present performance maps for our two models (RMSEs from the best time-scale and month combination for each county) along with examples of heat maps for a few selected counties illustrating the model performances for all combinations of considered time scales and months. The heat maps show that specific SPI or EDDI time-scales for specific months explained production anomalies better than others, as measured by the RMSE (Figs. 3 and 4; S-6 and S-7). In general, the SPI-SCVI model (Eq. (1)) performed best for alfalfa production in counties in eastern Montana and western North and South Dakota, where precipitation is the lowest in the domain (Fig. 3a). For this region of the study area, the model typically shows very low performance at any time-scale for the months of March to April, but has a sharp increase in model performance in May or June (Fig. 3a, heat map insets). This indicates that while production was sensitive to anomalies accumulated 5 to 11 months prior to the beginning of the growing season, it had low sensitivity to precipitation anomalies ending before May or to anomalies with long time scales. Eq. (1) explained better barley production anomalies for counties in central Montana and winter wheat production anomalies in central Montana, central North Dakota and western South Dakota (Fig. 3b and c). The EDDI-SCVI model (Eq. (2)) explained best alfalfa production anomalies in northern Idaho and western and eastern Montana (Fig. 4a) and explained better wheat and barley anomalies in the central and western parts of North and South Dakota (Fig. 4b and c).

Some counties showed similar sensitivities to a wide range of timescales and months. Furthermore, in some counties we detected the existence of autocorrelation in the SPI and EDDI time-scale series, which is reflected as diagonal banding structures of low RMSE, clearly visible for example in 3c. This correlation is produced when model configurations correlating months in the growing season maintain performance for increasing time-scales that incorporate the effect of climate anomalies occurring at earlier critical months. These issues can complicate the accurate identification of the characteristic time scales and months for the climatic variables. To reduce the noise in the representation of spatial patterns generated by the interaction between the timing and time-scale of the anomalies, we use time-scale brackets of short (1-5 months), moderate (6-10 months) and long (11-15 months) time-scales, and timing brackets of early (March-May), middle (June-July) and late (August-September) growing season.

Alfalfa production in eastern Montana, eastern Wyoming and the Dakotas, where Eq. (1) and Eq. (2) models performed well, responded at moderate to long SPI and EDDI time-scales (Fig. 4a and b). Response time-scales were shorter westward in central and western Montana and Idaho, where precipitation is higher, ETo is lower, and alfalfa production was less responsive to climatic anomalies. Barley production responded to a wide range of SPI time-scales throughout the year (see insets in Fig. 4c) and more counties had production sensitive to moderate and long time-scales than in the case of alfalfa. Counties with long time-scale response were mostly concentrated in central and eastern Montana and southern Idaho, where SPI-SCVI model (Eq. (1)) best explained production anomalies (Fig. 4c). The EDDI response timescales of barley production showed spatial patterns that were less clear (Fig. 4d). Like barley production, winter wheat also responded to a wide range of SPI and EDDI time-scales (between 1 and 15 months) throughout the year (see insets, Fig. 3c). Winter wheat production in southeastern Montana and South Dakota were most sensitive to SPI at medium and long time-scales, while North Dakota winter wheat production responded to shorter time-scales (Fig. 4e). Once more, sensitivities at long time-scales are concentrated in counties for which the SPI-SCVI model performed best. The spatial pattern of EDDI time-scales for winter wheat production were less informative (Fig. 4f) and somewhat similar to the spatial patterns of the barley time-scales. Generally, counties where crop production was most sensitive to precipitation were so at time-scales greater than 7 months, while counties where crop production was most sensitive to ETo were so at EDDI time-scales less than 6 months for the three crops. As discussed in the next section, the sensitivity of barley and winter wheat production to climatic factors was lower than for alfalfa and the role of price was more prominent in explaining production anomalies. This probably contributed to less structured spatial patterns of time-scales.

\subsection{Region-wide production sensitivity}

Since SPI, EDDI and SCVI are standardized indices, the coefficients of the statistical models provide a comparative measure of the sensitivity of crop production to precipitation and ETo. In general, and as expected, production for all crops was positively correlated with precipitation anomalies and inversely correlated with ETo anomalies (Fig. 5), although with exceptions for some crops and counties mostly in eastern Montana and North Dakota, as discussed later. Alfalfa production had the highest region-wide sensitivity to precipitation (mean SPI coefficient $\alpha=0.53$ ) and ETo (mean EDDI coefficient $\delta=-0.51$ ) with a relatively wide spatial variation (Fig. 5a). Barley and winter wheat production exhibited similar average sensitivities to precipitation (mean SPI coefficients $\alpha=0.34$ and $\alpha=0.37$, respectively) and ETo anomalies (mean EDDI coefficients $\delta=0.32$ and $\delta=0.2$, respectively). However, the sensitivity of barley production to climatologic drivers was more uniform across counties than winter wheat (Fig. $5 b$ and c).

Climate was the primary driver of alfalfa production anomalies with market prices having a much smaller influence. Surprisingly, the mean SCVI (price) coefficients in both the SPI and EDDI models were negative, although in both cases the variation of these coefficients among counties was relatively large and spanned a range of positive and negative values (Fig. 5a). Crop market prices played a much larger role on barley and winter wheat production, where the effect of price was on par with the effect of climate. Like with climate factors, the variation of SCVI factors in the study region was smaller for barley than for winter wheat (Fig. 5b and c). Notice the similarity of SCVI coefficients identified independently for each crop using Eq. (1) and Eq. (2), which indicates that the crop value and the climatologic indices are independent and shows the robustness of the models in identifying the unique influence of these indices on crop production variability.

We expected that crop irrigation practices had an effect on the sensitivity of crop production to precipitation and ETo variations, which would be reflected in the model coefficients and in the amount of production variance they can explain. To evaluate this expectation, we plotted the best performing model coefficients of each county against the amount of SCPI variance they explain and the fraction of irrigated production in the county (Fig. 6). The sensitivity of alfalfa production to climatic drivers is reflected in the clear direct correlation between the amount of the SCPI variance explained by the Eq. (1) and the magnitude of the SPI coefficient (Fig. 6a), and the clear inverse correlation 


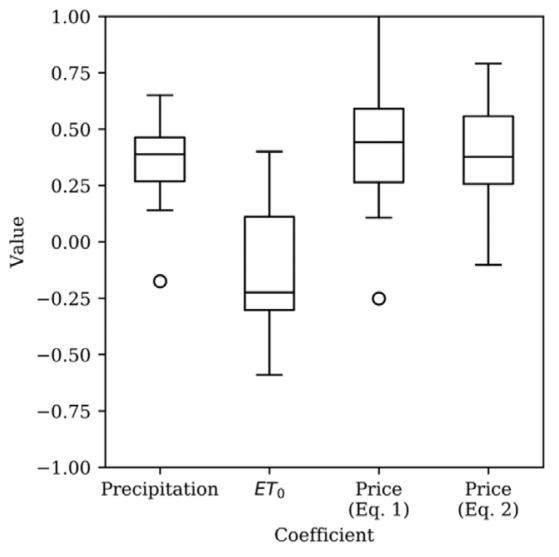

(a)

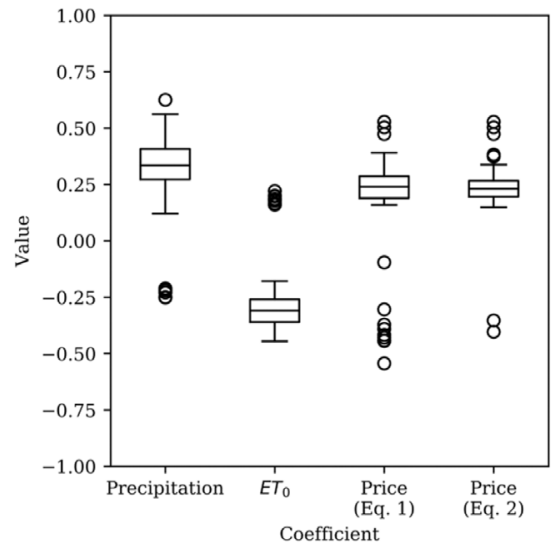

(b)

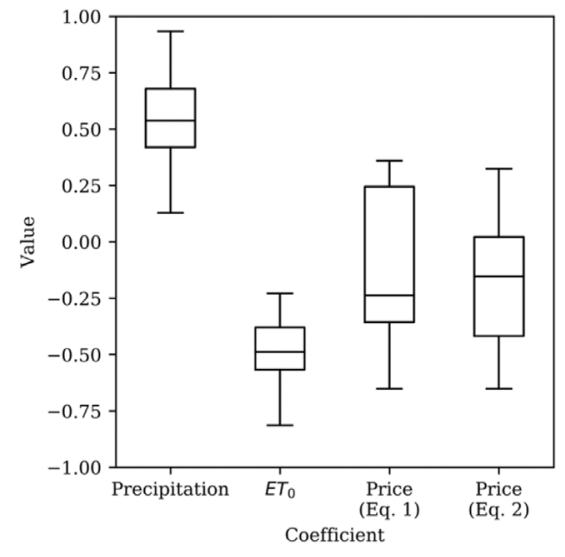

(c)

Fig. 5. Boxplots of significant coefficients for the study area for alfalfa (a); barley (b), and; winter wheat production (c).

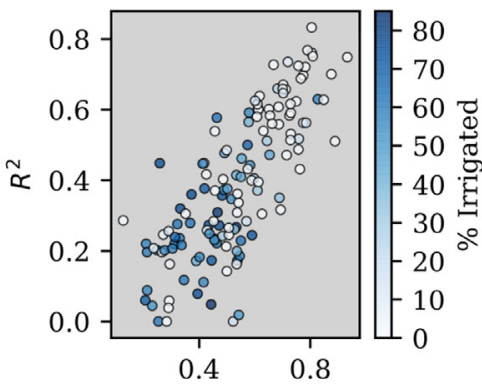

Precipitation Coefficient $(\alpha)$

(a)

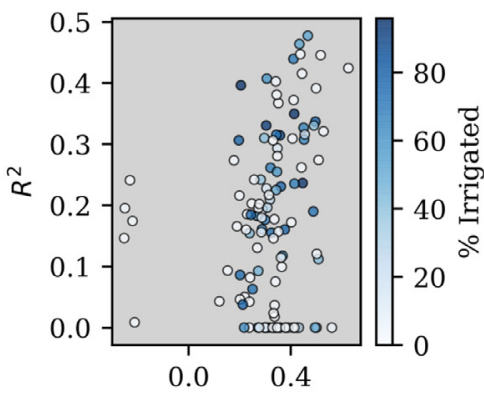

Precipitation Coefficient $(\alpha)$

(c)

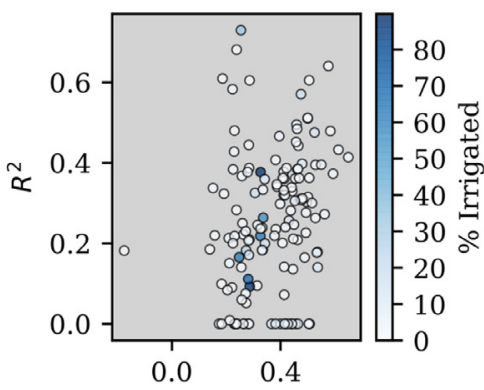

Precipitation Coefficient $(\alpha)$

(e)

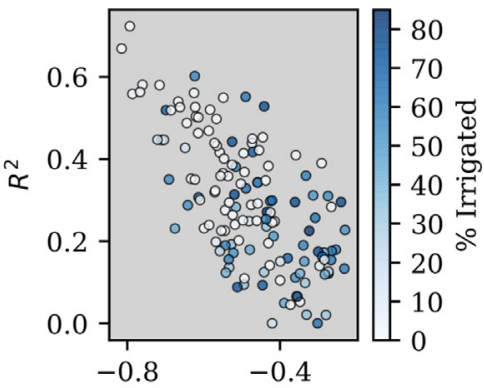

$E T_{0}$ Coefficient $(\delta)$

(b)

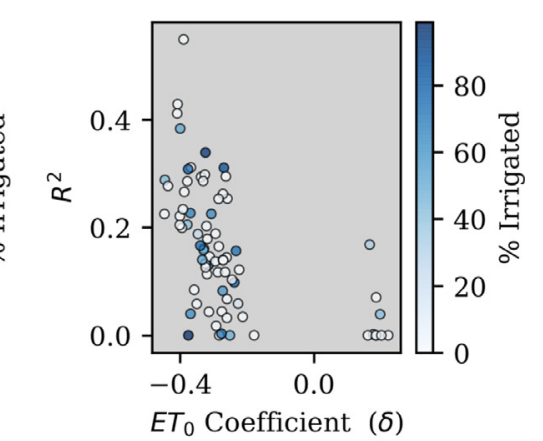

(d)

Fig. 6. Explained variance of crop production anomalies vs. climatic coefficients vs. fraction of irrigated production for Eq. (1) (left) and Eq. (2) (right) for alfalfa (a

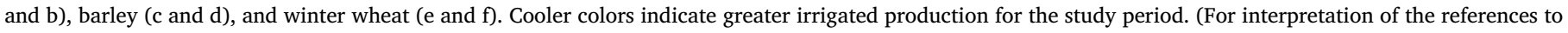
color in this figure legend, the reader is referred to the web version of this article.) 
between the amount of the SCPI variance explained by Eq. (2) and the magnitude of the EDDI coefficient (Fig. 6b). In these figures it is clear that counties with a higher percentage of irrigated alfalfa had a lower sensitivity to the climatic drivers and a smaller fraction of the production variance explained by the models. This illustrates that irrigation to a large extent decouples alfalfa production from the climatic conditions. Primarily irrigated counties had a mean SPI coefficient of $\alpha=0.40$ and a mean EDDI coefficient of $\delta=-0.40$ and, on average, explained about $26 \%$ of the production variance respectively. This contrasts with the substantially higher sensitivity of primarily rain-fed counties (mean SPI coefficient $\alpha=0.60$ and mean EDDI coefficient $\delta=-0.52$ ) and the ability of the models to explain production variability (mean $R 2=47$ with Eq. (1) and mean $R 2=33$ with Eq. (2)).

The situation is different for barley and winter wheat. The amount of explained variance in barley production is less correlated with the climatic coefficients (Fig. $6 \mathrm{c}$ and d) than in the alfalfa case, which also indicates that barley production is to some extent decoupled from the climatic drivers, and the reduced sensitivity of production to climatic fluctuations were caused by the effect of crop prices and not the effect of irrigation. Heavily irrigated counties were found along the entire range of model performances and coefficients for both the SPI and EDDI based models. There was little difference between precipitation coefficients in primarily irrigated counties and primarily rain-fed counties ( $\alpha=0.34$ and 0.31 , respectively). The EDDI based model produced similar mean R2 value in primarily irrigated counties (17\%) to primarily rain-fed counties (16\%). This indicated that barley production benefited less from irrigation than alfalfa other than some protection from fluctuations in ETo. Winter wheat also exhibited low correlation between the climatic coefficients and the amount of variance explained by the models. Similar to barley, the lower sensitivity of wheat production to climatic drivers was also caused by the compensatory effect of wheat market prices. Irrigation of winter wheat is uncommon in the region, which did not permit to evaluate the buffering effect that irrigation had on this crop.

\subsection{Spatial patterns of production response}

The analysis of results presented in the previous section can be extended to investigate the existence of spatial patterns of sensitivity and production response. Fig. 7 shows the spatial distribution of the optimal SPI $(\alpha)$ and EDDI $(\beta)$ coefficients for alfalfa, barley, and winter wheat. SPI coefficients for alfalfa production were significant in 138 of the 182 counties that reported alfalfa production, with most non-significant coefficients associated with counties in southern Idaho and western Wyoming.

Maximum sensitivity of alfalfa production to precipitation anomalies occurred in the dryer and rain-fed counties of eastern Montana, eastern Wyoming, western North Dakota, and western South Dakota (Fig. 7a). The highest SPI coefficient ( $\alpha=0.93$ ) was found in counties in western North Dakota. For these counties the SPI-SCVI model (Eq. (1)) explained around $75 \%$ of the variance in alfalfa production. The sensitivity of alfalfa production then decreased again further east into the rain-fed but wetter eastern half of North Dakota, where precipitation anomalies explained only between $25 \%$ and $30 \%$ of the production variance. The spatial patterns of sensitivity of alfalfa production to ETo variations were similar to those of precipitation; alfalfa production was most sensitive in the driest counties of the study area located in eastern Montana, eastern Wyoming, North and South Dakota. In these counties, ETo anomalies explained about $67 \%$ of the variations in alfalfa production. Sensitivity was lowest in Idaho, where irrigated production dominates, and in eastern North Dakota where climate transitions to the rainy conditions of the US Midwest US region. In these counties with low sensitivity the EDDI-SCVI (Eq. (2)) model explained about $30 \%$ of the variance of alfalfa production.

The sensitivity of barley production to precipitation and ETo was more spatially homogeneous (Fig. 7c and d). Although the $\alpha$ precipitation coefficients were statistically significant for 120 out of the 190 counties that reported barley production, the coefficients did not reveal clear spatial patterns of variation. This is consistent with the findings mentioned earlier that the larger importance of crop market drivers reduced the sensitivity of barley production to precipitation variability. The relatively flat spatial distribution of the precipitation coefficients may be a result of crop prices being spatially invariant at the state scale and also a result of the marginal benefits that irrigation has on barley production. Finally, significant ETo coefficients were mostly concentrated in the counties of North Dakota, with little variation between them.

SPI coefficients reflecting the sensitivity of winter wheat production to precipitation anomalies were significant in 138 out of the 185 counties that reported winter wheat in the study region (Fig. 7e). Counties in south-central South Dakota and eastern Wyoming exhibited the highest sensitivity to precipitation $(\alpha>0.6)$ and in these counties the SPI-SCVI model (Eq. (1)) explained about $40 \%$ of the production variance. On the other hand, winter wheat production in North Dakota showed the lowest sensitivity. The regions where production was most sensitive to variations in precipitation also showed the highest inversely proportional sensitivity to EDDI (more ETo decreased production). In these counties, $\delta$ coefficients reached -0.6 and Eq. (2) explained up to $51 \%$ of the variance. However, production in Northern and Eastern North Dakota, which exhibited low sensitivity to precipitation variability, showed a positive response to EDDI (more ETo improved production (Fig. 7f). For the counties where production had positive correlation with EDDI, Eq. (2) explained between $12 \%$ and $20 \%$ of the production index variance.

Crop prices influence farmer decision-making and can reduce the apparent effect of climatic anomalies on crop production. The spatial variations in the modulating effect of commodity prices on crop production is shown in Fig. 8. Alfalfa production did not show significant sensitivity to prices in most counties, so the figure only shows the distribution of the $\beta$ SCVI sensitivity factors for barley and winter wheat. In all cases, the coefficients estimated by Eq. (1) and (2) were very similar both spatially an in magnitude (Fig. 8), which indicates that the crop price dynamics used in the SCVI are statistically independent of the precipitation and ETo dynamics represented by the SPI and EDDI.

SCVI coefficients for barley obtained from Eq. (1) and (2) indicated that barley production increased with the crop price received by farmers the previous year in most counties in Montana, Idaho and Wyoming and that this sensitivity was somewhat higher in the western part of Montana and in Idaho (most clearly noticeable in Fig. 8b), where irrigated production was most dominant, and in some of the easternmost counties of North Dakota. Although mostly statistically non-significant, both Eq. (1) and (2) agreed that barley production in most counties in central and western North Dakota and in South Dakota had an inverse relationship with prices received the previous year. On the other hand, winter wheat production was most sensitive to price, particularly in central North Dakota and northeastern Montana (Fig. 8c and d). In these counties crop prices had more weight on production than SPI and EDDI, particularly in North Dakota.

\subsubsection{Clustering analysis}

Fig. 9a shows the classification of counties with respect to the sensitivity of alfalfa production to precipitation, climate and crop price. The violin plots (Fig. 9b) provide information on the combination of factors that characterize each cluster. Cluster 1 (blue) groups counties where alfalfa production was most sensitive to variations in precipitation and ETo the lowest sensitivity to price. Counties in Cluster 1 were primarily rain-fed and located in North Dakota, South Dakota, northeast Wyoming, and eastern Montana, the regions with lowest average precipitation in the study area. Cluster 2 (green) are counties with more moderate sensitivity to climate but some positive response to crop 


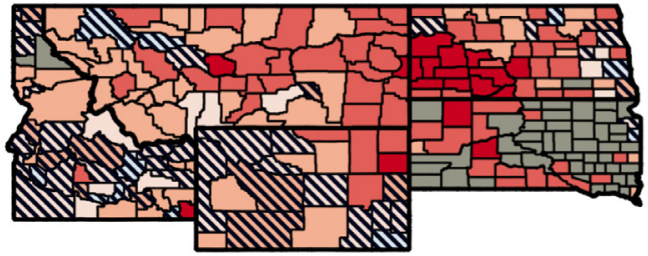

(a)

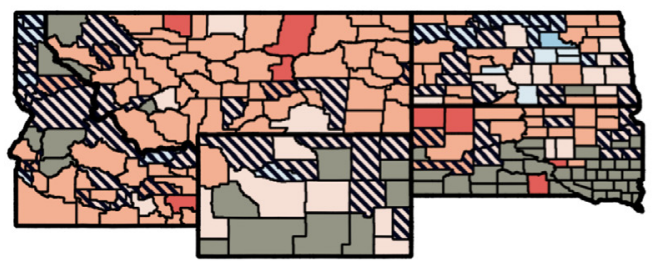

(c)

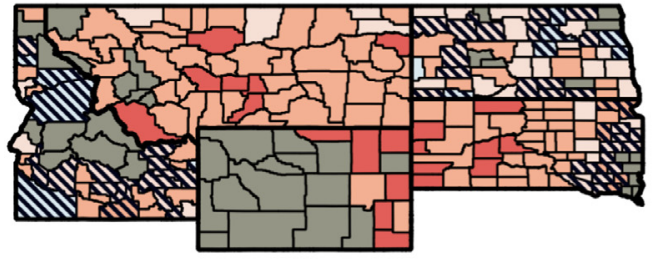

(e)

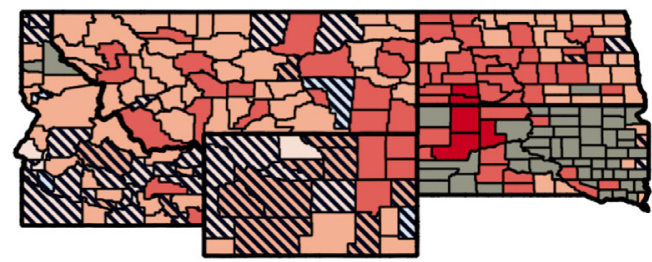

(b)

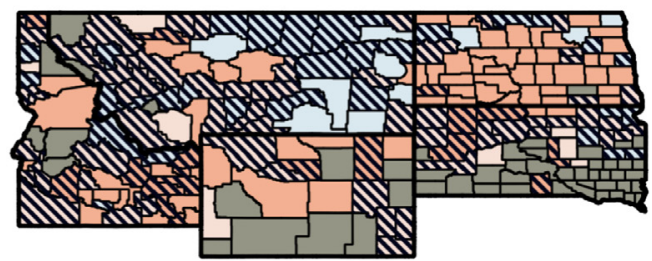

(d)

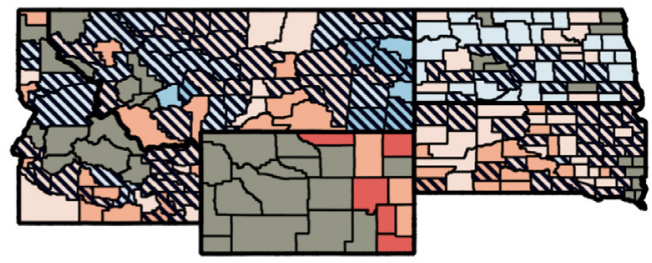

(f)
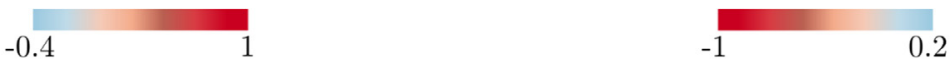

Fig. 7. Spatial distribution of precipitation coefficients, $\alpha$ (left column) and ETo coefficients, $\delta$ (right column) for alfalfa (a) and (b), barley (c) and (d), and winter wheat (e) and (f). The scale describes the relative sensitivity of climatic anomalies, where warmer colors indicate a negative response of crop production to negative precipitation anomalies or positive ETo anomalies (i.e., negative response to drought), and cooler colors indicate a positive response in crop production anomalies to negative precipitation anomalies or positive ETo anomalies (i.e., positive response to drought). The diagonal lines across counties indicate non-significant sensitivity factors. (For interpretation of the references to color in this figure legend, the reader is referred to the web version of this article.) price. Counties in this cluster are mostly located in central and western Montana. Cluster 3 (gold) groups counties with the highest resiliency to precipitation and ETo variability, and also an inverse relationship with crop price. Counties in this cluster are mostly located in Idaho, Wyoming, eastern North Dakota, and South Dakota, which are regions with the highest precipitation rates in the domain. In the case of Idaho and western Wyoming, most of the alfalfa production is irrigated.

The distribution of clusters for barley is different than for alfalfa
(Fig. 10a). Cluster 1 is associated with counties that had a direct response to precipitation anomalies and an inverse response to ETo anomalies and a relatively variable but positive sensitivity to crop price (Fig. 10b). Cluster 1 includes counties in the mountainous regions of western Montana, Idaho and Wyoming as well as in South Dakota. Cluster 2 is characterized by counties where barley production had a relatively low and variable sensitivity to precipitation, moderate sensitivity to ETo and a negative response to price. Counties in Cluster 2

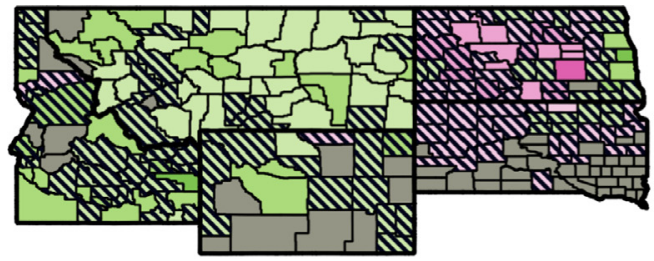

(a)

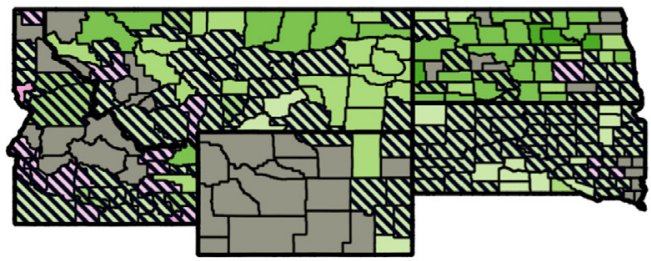

(c)
$-0.75$

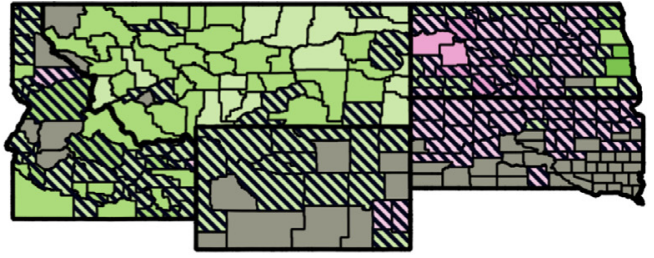

(b)

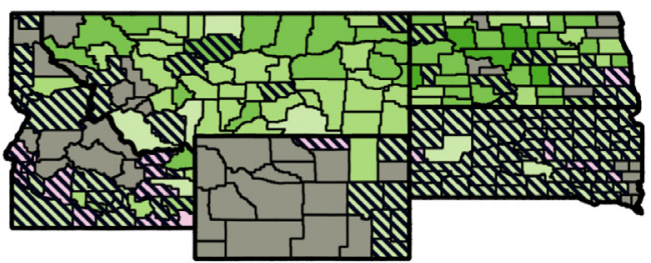

(d)

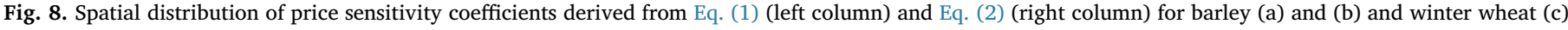

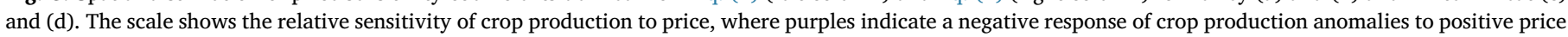

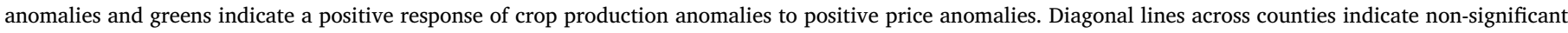
coefficients. Price coefficients for alfalfa (not shown) were non-significant in most counties. 

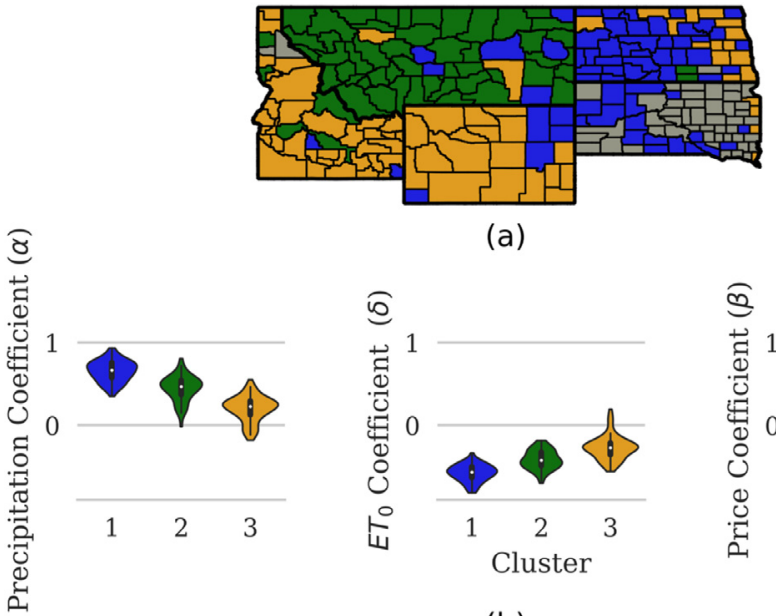

(a)
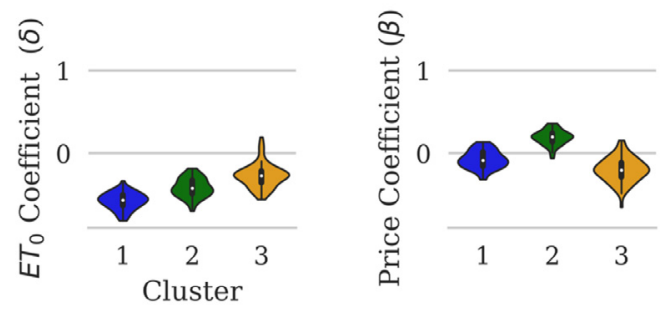

Fig. 9. (a) County classifications based sensitivity of alfalfa production to SPI, EDDI and SCVI; (b) violin plots with distribution of precipitation sensitivity coefficients (left), ETo sensitivity coefficient, (middle), and price sensitivity coefficients (right) for clusters 1 (blue), 2 (green) and 3 (orange). (For interpretation of the references to color in this figure legend, the reader is referred to the web version of this article.)

(b)

are largely located in central and western North Dakota. Cluster 3 is unique in that it is characterized by counties that had a relatively high positive response to precipitation and crop price anomalies (like Cluster 1) but also had a positive response to ETo anomalies (i.e. production increased with increased ETo). Counties in this cluster were mostly located in central and eastern Montana.

Finally, the classification of winter wheat counties is shown in Fig. 11a. Cluster 1 are counties where production is minimally impacted by climatic or price factors, and are mostly found across much of Idaho and near the wetter eastern borders of North Dakota and South Dakota. Cluster 2 is mostly characterized by high sensitivity to crop price, but also to a positive response both precipitation and ETo anomalies. Clusters 2 is mostly composed of counties in Eastern Montana and much of North Dakota. Cluster 3 are the counties most vulnerable to precipitation and ETo anomalies, with a relatively lower response to price. Counties with these characteristics occupy central and western North Dakota, eastern Wyoming, and central Montana.

\section{Discussion}

Our study characterized the sensitivity of agricultural production to these two major climatic drivers, while controlling for the effect that crop prices have on farmer decisions. This is a key aspect that is often ignored in studies seeking to assess drought impacts on food production and food security. Farmers not only respond to climatic factors, but are also sensitive to economic drivers and may choose to maintain production by increasing acreage even under adverse climatic conditions if markets are favorable (Maneta et al., 2009; Miao et al., 2016). We showed that crop prices reduced the sensitivity of production to climate, inducing compensatory effects on production that reduce the local impact of climate fluctuations (Fig. 11b, cluster 2). Ignoring the effect of economic drivers on farmer choices may introduce biases in the share of observed production declines attributed to drought. However, it should be recognized that climate external to the region can impact crop prices within the region (Adams et al., 1998). Our regional focus provides different insights compared to findings from previous studies that have focused on characterizing drought impacts on yields (Hlavinka et al., 2009; Peña-Gallardo et al., 2018b; Zipper et al., 2016). The focus on production was motivated by the idea that integrating agricultural yield and area in production is a better immediate measure of food security than yield because it captures the decisions farmers make both at the intensive margin (resource allocation to increase yield) and at the extensive margin (land reallocation).

Comparing our results with previous studies, we found that the climatic time-scales at which yield responds are generally shorter than those of production. Zipper et al. (2016) reported that maize and soy yield anomalies in the US were most correlated with drought conditions occurring during July and August over time-scales of 1-3 months, or about 1-2 months prior to harvest. Vicente-Serrano et al. (2006) reported that wheat and barley yields in Spain were most responsive to SPI time scales between 1 and 3 months in February, which is 4 months prior to harvest, and reflects the importance of delayed processes that affect crop development such as the timing of soil moisture recharge and of crop water use. More recently, Peña-Gallardo et al. (2018b) applied the SPEI to analyze the yield response to drought for the major crops in the US. The results for barley and winter wheat indicated a

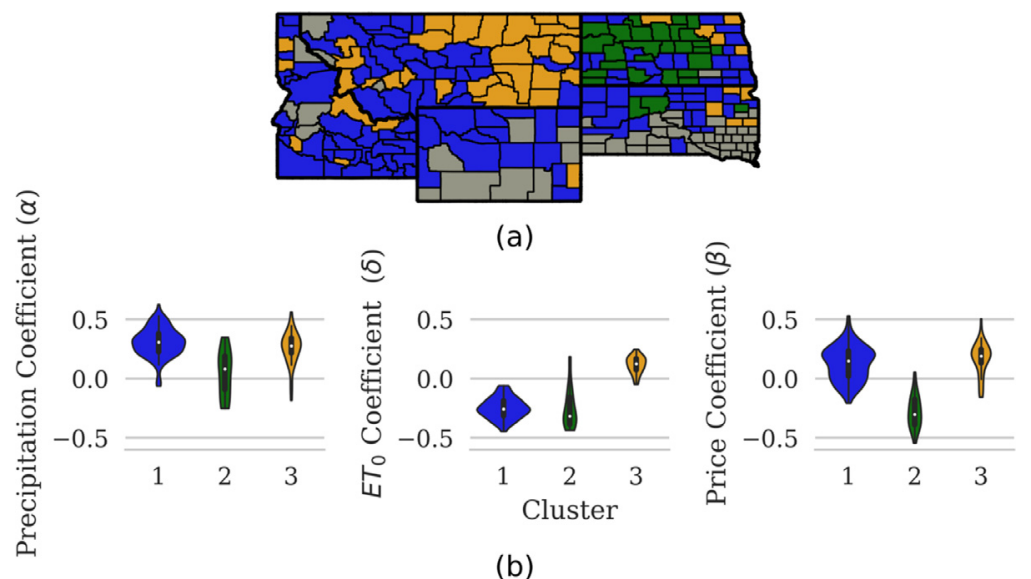

Fig. 10. Same as Fig. 10 but for barley. (For interpretation of the references to color in this figure legend, the reader is referred to the web version of this article.) 

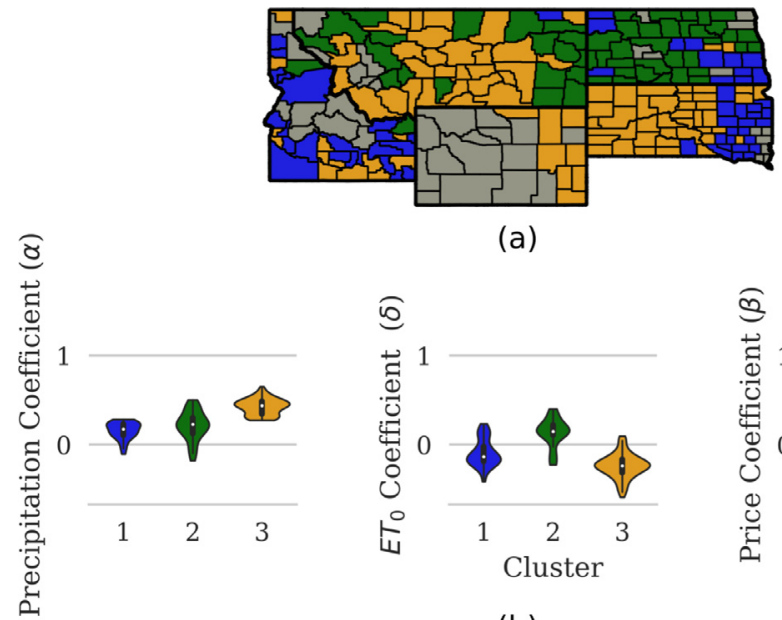

(a)
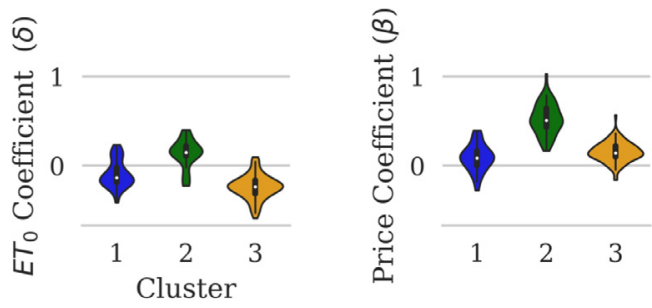

(b)

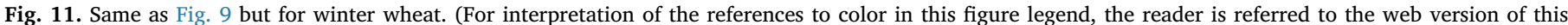
article.)

response at a wide range of time-scales, often longer than three months. The time-scales identified in our study are generally longer than that reported for yields. This is likely due to our focus on production which is a function of both yield and cropping area. The longer characteristic time scales indicate that crop production has more inertia and responds more slowly than yield to climate fluctuations. This is because farmers consider not only short term climate conditions, but also other types of information such as seasonal forecasts, traditional knowledge, or crop market values in their decision making months before the crops are sown.

This relatively long time scale of farmer decision making is consistent with studies looking at farmer behavior. For instance, (Haigh et al., 2015) found that over $80 \%$ of farmers in the US Corn Belt decided on cropping area between mid-fall and late-winter, and that over $50 \%$ of the same farmers used current, monthly or seasonal drought forecasts to aid in their decisions. However, other factors not related to farmer decision making such as specific crop cultivars, varieties and other physiological processes can also play a role in these time scales. (Vicente-Serrano et al., 2013) showed that longer time-scales were associated with semiarid or subhumid regions possibly because of physiological adaptations to drought.

The spatial patterns of sensitivity exhibited by each crop reflects what crops and regions are more driven by precipitation and ETo and thus exposed to drought and which ones are more decoupled from climatic conditions. Alfalfa was mostly sensitive to precipitation anomalies, slightly less to ETo, and had little sensitivity to price (Fig. 5). Unlike wheat and barley, ranchers grow alfalfa to feed cattle and continue producing it regardless of the price. In addition, alfalfa is a perennial crop that is usually not rotated at least until the stand is depleted, often not before 4-5 years. As a consequence, land allocation to alfalfa tends to be more stable through time than land allocated to wheat or barley. These factors may contribute to the observed low sensitivity of alfalfa production to price. The spatial distribution of sensitivity to precipitation or ETo (Fig. 7) generally coincided with gradients in precipitation (Fig. 1c), temperature (Fig. 1d), and the prevalence of irrigation across the study area. Crop yields in warmer regions are generally more sensitive to climatic variability than cooler regions (Lobell et al., 2011), and this affects the sensitivity of production even if the amount of land allocated to this crop remains constant.

Barley and winter wheat cultivated in the region, on the other hand, are annual crops often rotated in the same field. The land allocated to these crops are more variable year to year and subject to farming decisions based on both climatic and market factors. This aspect was clearly captured by the relatively high sensitivity of these crops to crop price (Fig. 8). The spatial patterns of sensitivity of barley and winter wheat production to climatic factors did not clearly follow the spatial gradients of precipitation or temperature, and the sensitivity was not affected by the amount of irrigation in the county (Fig. 6c and d). It is possible that variations in soil water retention properties, shallow groundwater, farming practices and other variables not considered in the model exert a larger influence on production than climate and dominate the spatial distribution of sensitivities. Using county level yield data, Li and Troy (2018) and Troy et al. (2015) found that winter wheat yields in the US Northern Rockies and Northern Plains showed limited response to growing season precipitation, and that for a variety of crops, the benefit of irrigation in terms of yield gains was often limited. Although they did not specifically analyze barley, we could speculate that given the prevalence of rain-fed production, soil moisture recharge during spring and growing season from precipitation is sufficient to obtain barley yields close to the potential. This would explain why the sensitivity of barley production to the SPI was similar for counties with different levels of irrigated production.

The spatial distribution of barley and winter wheat production sensitivities to EDDI brought forward some interesting patterns. Winter wheat production over north and eastern North Dakota (Fig. 7f), and barley production over north central Montana showed a somewhat positive response to increased atmospheric water demand (Fig. 7d). This positive crop production response to high ETo anomalies observed in this study for barley and winter wheat was also observed by Lobell and Asner (2003) and Zipper et al. (2016) for corn and soybean yields, where increased crop yields occurred during periods of below average precipitation or above average atmospheric water demand. Zipper et al. (2016) attributed this positive sensitivity to drought conditions to shallow groundwater and poorly drained soils, or the presence of irrigation. The positive response to high ETo in our study area occurred in counties were minimal irrigation of barley and winter wheat was present. However, the transition between the dry western US and the wet midwest occurs roughly north to south through western North Dakota where annual precipitation equals ETo (Salley et al., 2016). In the case of North Dakota, waterlogging and poor field drainage is often an issue and production may benefit from increased ETo. However, unlike the rest of the western US, eastern Montana and North Dakota are experiencing a reduction in atmospheric vapor pressure deficit (Ficklin and Novick, 2017) and an increase in summer precipitation (Holden et al., 2018), which may result in barley and winter wheat production declines based on the positive production response to lower precipitation and increased ETo observed in this study. Further work concerning historic sensitivity to climatic anomalies in conjunction with historic 
trends in atmospheric water supply and demand would provide useful insights into how the equilibrium between crop production and climate variability could shift in the future.

The use of drought indices to characterize the sensitivity of crop production or yield is providing important insights that are helping understand the risk of climate change on agriculture (Peña-Gallardo et al., 2018b; Wang et al., 2014; Yamoah et al., 2000; Zipper et al., 2016). Most of these studies focus on the impact of precipitation anomalies using the SPI or use the SPEI, which incorporates the simultaneous effect of precipitation and ETo anomalies. We developed different models using the SPI and EDDI to study the sensitivity of precipitation and ETo separately. This elucidates the individual effects of these climatic drivers, but does not capture the interactions between the two. Our analysis revealed that the sensitivity of production to both constituents of climatic extremes were similar but opposite in sign, particularly for alfalfa and barley but also for winter wheat (Fig. 5). This symmetry of precipitation and ETo about zero sensitivity indicates that these drivers are correlated and play similar roles in driving terrestrial processes, which supports the hypothesis proposed by VicenteSerrano et al. (2010) in their development of the SPEI. SPEI has often been found to produce higher correlations between climatic conditions and vegetation production than other drought indices (Beguería et al., 2014; Peña-Gallardo et al., 2018a; Vicente-Serrano et al., 2012), demonstrating the added value of this metric and its ability to capture synergistic interactions between precipitation and ETo. However, our research showed that while the impacts of precipitation and ETo on production are similar in magnitude and upholds one of the premises embedded in the SPEI, the timing and time-scales at which the precipitation or ETo are most correlated with production are often not the same. Production tends to be correlated with precipitation anomalies at longer time-scales and responds to ETo at shorter time-scales. This information is lost if the SPEI is used alone and shows that the SPI and EDDI or SEDI may provide complementary information if used in conjunction with the SPEI.

\section{Conclusion}

Alfalfa and barley for stockfeed and wheat production are major contributors to the economy of the Northern Great Plains region of the US. These three crops comprise the largest regional share of agricultural land and are important to maintain the food supply of the country and of the globe. How- ever, limited crop diversification and the prevalence of dryland production makes this region vulnerable to drought and crop market downturns. Evaluating agricultural resilience is key to identifying what regions may require strategies to promote adaptation and mitigate the negative impacts of drought or regional climate shifts. Our analysis contributes to understanding agricultural sensitivity to climate in a novel way for two reasons: First, it simultaneously considers the impacts of climatic and agricultural market anomalies on crop production; and second it focuses on production rather than on crop yield to captures both the biophysical response of the crop and the land allocation and harvesting choices farmers make, which is important for resiliency analysis.

In general, for the region, we identified that agricultural production was most vulnerable to drought in eastern Montana and western North and South Dakota, especially for alfalfa. The intermountain western region (western Montana and Idaho) and the wetter eastern part of the Dakotas showed more resiliency to precipitation shortfalls. Alfalfa production was most sensitive to climate, and the spatial pattern of sensitivity followed the spatial distribution of precipitation and temperature. Sensitivity of alfalfa production to EDDI was secondary to SPI, while barley and winter wheat production had a larger relative sensitivity to EDDI and to market prices. This sensitivity to prices illustrates that farmers may choose to sustain production by increasing the land allocated to specific products even under suboptimal climatic conditions if crop prices in previous years have been favorable. The analysis also shows that evaluations of the impact of climate on agricultural production can be biased if crop prices and other farmer incentives are not taken into account.

We also detected that agricultural production had a longer inertia to climatic variations compared to yields, as reflected by the longer optimal climatic time-scales we found compared to these reported by yield studies using similar indices. This is an additional indication that farmers choices can sustain production under unfavourable conditions by increasing the level of inputs (e.g. fertilizer, labor) or increasing land allocation, which increases the resiliency of crop production. Finally, while in most cases the sensitivity of production to precipitation and ETo was similar in magnitude, time-scales of SPI were longer than the time scales of EDDI. We interpreted that the SPI reflects the effect of moisture supply to plants, which is mediated by the soil and therefore has relatively longer response time scales. EDDI on the other hand reflects the effect of atmospheric moisture demand, which introduces a more immediate physiological response on the crop, and this is reflected in the shorter EDDI time-scales.

\section{Acknowledgments}

This work has been supported by the United States Department of Agriculture, USDA-NIFA research grant 2016-67026-25067, and by the NASA EPSCoR program research grant 80NSSC18M0025. P.W. also acknowledges partial support from the NSF EPSCoR cooperative agreement EPS-1101342.

\section{Supplementary material}

Supplementary material associated with this article can be found, in the online version, at doi:10.1016/j.agrformet.2019.107778.

\section{References}

Abatzoglou, J.T., 2013. Development of gridded surface meteorological data for ecological applications and modelling. Inter. J. Clim. 33, 121-131. https://doi.org/10. 1002/joc.3413.

Adams, R., Hurd, B., Lenhart, S., Leary, N., 1998. Effects of global climate change on world agriculture: an interpretive review. Clim. Res. 11, 19-30. https://doi.org/10. 3354/cr011019.

Beguería, S., Vicente-Serrano, S.M., Reig, F., Latorre, B., 2014. Standardized precipitation evapotranspiration index (SPEI) revisited: parameter fitting, evapotranspiration models, tools, datasets and drought monitoring. Int. J. Climatol. 34, 3001-3023. https://doi.org/10.1002/joc.3887.

Betancourt, M., Girolami, M., 2015. Hamiltonian Monte Carlo for hierarchical models. In: Upadhyay, S.K., Singh, U., Dey, D., Loganathan, A. (Eds.), Current Trends in Bayesian Methodology with Applications. CRC Press, Boca Raton, FL, pp. 79-97.

Daly, C., Halbleib, M., Smith, J.I., Gibson, W.P., Doggett, M.K., Taylor, G.H., Curtis, J., Pasteris, P.P., 2008. Physiographically sensitive mapping of climatological temperature and precipitation across the conterminous United States. Int. J. Climatol. 28, 2031-2064. https://doi.org/10.1002/joc.1688.

Ficklin, D.L., Novick, K.A., 2017. Historic and projected changes in vapor pressure deficit suggest a continental-scale drying of the United States atmosphere. J. Geophys. Res. 122, 2061-2079. https://doi.org/10.1002/2016JD025855.

Gelman, A., Carlin, J.B., Stern, H.S., Dunson, D.B., Vehtari, A., Rubin, D.B., 2013 Bayesian Data Analysis, 3rd ed. CRC Press, Boca Raton, FL.

Haigh, T., Takle, E., Andresen, J., Widhalm, M., Carlton, J.S., Angel, J., 2015. Mapping the decision points and climate information use of agricultural producers across the U.S. Corn. Belt. Clim. Risk Manag. 7, 20-30. https://doi.org/10.1016/j.crm.2015.01. 004.

Hartigan, J.A., Wong, M.A., 1979. Algorithm as 136: A K-Means clustering algorithm. Appl. Stat. 28, 100. https://doi.org/10.2307/2346830.

Heim, R.R., 2002. A review of Twentieth- Century Drought indices used in the United States. Bull. Am. Meteorol. Soc. 83, 1149-1165. https://doi.org/10.1175/15200477(2002)083<1149:AROTDI > 2.3.CO;2.

Hennessy, D.A., 2006. On monoculture and the structure of crop rotations. Am. J. Agric. Econ. 88, 900-914. https://doi.org/10.1111/j.1467-8276.2006.00905.x.

Hlavinka, P., Trnka, M., Semerádová, D., Dubrovský, M., Žalud, Z., Možný, M., 2009. Effect of drought on yield variability of key crops in Czech Republic. Agric. For. Meteorol. 149, 431-442. https://doi.org/10.1016/j.agrformet.2008.09.004.

Hobbins, M.T., Wood, A., McEvoy, D.J., Huntington, J.L., Morton, C., Anderson, M., Hain, C., 2016. The evaporative demand drought index. Part I: linking drought evolution to variations in evaporative demand. J. Hydrometeorol 17, 1745-1761. https://doi.org/ 10.1175/JHM-D-15-0121.1.

Holden, Z.A., Swanson, A., Luce, C.H., Jolly, W.M., Maneta, M., Oyler, J.W., Warren, 
D.A., Parsons, R., Affleck, D., 2018. Decreasing fire season precipitation increased recent western US forest wildfire activity. Proc. Natl. Acad. Sci. 201802316. https:// doi.org/10.1073/pnas.1802316115.

Iizumi, T., Ramankutty, N., 2015a. How do weather and climate influence cropping area and intensity? Glob. Food Sec. 4, 46-50. https://doi.org/10.1016/j.gfs.2014.11.003.

Iizumi, T., Ramankutty, N., 2015b. How do weather and climate influence cropping area and intensity? Glob. Food Sec. 4, 46-50. https://doi.org/10.1016/j.gfs.2014.11.003.

Kim, D., Rhee, J., 2016. A drought index based on actual evapotranspiration from the bouchet hypothesis. Geophys. Res. Lett. 43, 10277-10285. https://doi.org/10.1002/ 2016GL070302.

Lanning, S.P., Kephart, K., Carlson, G.R., Eckhoff, J.E., Stougaard, R.N., Wichman, D.M., Martin, J.M., Talbert, L.E., 2010. Climatic change and agronomic performance of hard red spring wheat from 1950 to 2007. Crop. Sci. 50, 835. https://doi.org/10. 2135/cropsci2009.06.0314.

Lawrence, P.G., Maxwell, B.D., Rew, L.J., Ellis, C., Bekkerman, A., 2018. Vulnerability of dryland agricultural regimes to economic and climatic change. Ecol. Soc. 23. https:// doi.org/10.5751/ES-09983-230134.

Li, X., Troy, T., 2018. Changes in rainfed and irrigated crop yield response to climate in the western US OPEN ACCESS changes in rainfed and irrigated crop yield response to climate in the western US. Environ. Res. Lett. 13.

Lobell, D.B., Asner, G.P., 2003. Climate and management in U.S. agricultural yields. Science 299, 1032. https://doi.org/10.1126/science.1078475.

Lobell, D.B., Field, C.B., 2007. Global scale climate-crop yield relationships and the impacts of recent warming. Environ. Res. Lett. 2. https://doi.org/10.1088/1748-9326/ 2/1/014002.

Lobell, D.B., Ortiz-Monasterio, J.I., Sibley, A.M., Sohu, V.S., 2012. Satellite detection of earlier wheat sowing in India and implications for yield trends. Agric. Syst. 115, 137-143. https://doi.org/10.1016/j.agsy.2012.09.003.

Lobell, D.B., Schlenker, W., Costa-Roberts, J., 2011. Climate trends and global crop production since 1980. Science 333, 616-620. https://doi.org/10.1126/science. 1204531.

Maneta, M.P., Torres, M.O., Wallender, W.W., Vosti, S., Howitt, R., Rodrigues, L., Bassoi, L.H., Panday, S., 2009. A spatially distributed hydroeconomic model to assess the effects of drought on land use, farm profits, and agricultural employment. Water Resour. Res. 45. https://doi.org/10.1029/2008WR007534.

McKee, T.B., Doesken, N.J., Kleist, J., 1993. The relationship of drought frequency and duration to time scales. In: AMS 8th Conf. Appl. Climatol.

McMahon, S.M., Diez, J.M., 2007. Scales of association: hierarchical linear models and the measurement of ecological systems. Ecol. Lett. 10, 437-452. https://doi.org/10 1111/j.1461-0248.2007.01036.x.

Miao, R., Khanna, M., Huang, H., 2016. Responsiveness of crop yield and acreage to prices and climate. Am. J. Agric. Econ. 98, 191-211. https://doi.org/10.1093/ajae/ aav025.

Mitchell, K.E., 2004. The multi-institution North American Land Data Assimilation System (NLDAS): utilizing multiple GCIP products and partners in a continental distributed hydrological modeling system. J. Geophys. Res. 109, D07S90. https://doi. org/10.1029/2003JD003823.

Mukherjee, S., Mishra, A., Trenberth, K.E., 2018. Climate change and drought: a perspective on drought indices. Curr. Clim. Chang. Rep. 4, 145-163. https://doi.org/10. 1007/s40641-018-0098-x.

Palmer, W.C., 1965. Meteorological Drought. U.S. Dep. Commer Weather Bur. Res. Pap. 45.

Pasho, E., Camarero, J.J., de Luis, M., Vicente-Serrano, S.M., 2011. Impacts of drought at different time scales on forest growth across a wide climatic gradient in north-eastern Spain. Agric. For. Meteorol. 151, 1800-1811. https://doi.org/10.1016/j.agrformet. 2011.07.018.

Peña-Gallardo, M., Vicente-Serrano, S., Domínguez-Castro, F., Quiring, S., Svoboda, M., Beguería, S., Hannaford, J., 2018. Effectiveness of drought indices in identifying impacts on major crops over the USA. Clim. Res. https://doi.org/10.3354/cr01519.

Peña-Gallardo, Mrina, Vicente-Serrano, S.M., Domínguez-Castro, F., Quiring, S., Svodoba, M., Beguería, S., Hannaford, J., 2018a. Effectiveness of drought indices in identifying impacts on major crops across the USA. Clim. Res. 75, 221-240. https://doi.org/10. 3354/cr01519.
Peña-Gallardo, Marina, Vicente-Serrano, S.M., Quiring, S., Svoboda, M., Hannaford, J. Tomas-Burguera, M., Martín-Hernández, N., Domínguez-Castro, F., El Kenawy, A., 2018b. Response of crop yield to different time-scales of drought in the United States: spatio-temporal patterns and climatic and environmental drivers. Agric. For. Meteorol. 264, 40-55. https://doi.org/10.1016/j.agrformet.2018.09.019.

Porter, J.R., Semenov, M.A., 2005. Crop responses to climatic variation. Philos. Trans. R. Soc. B Biol. Sci. 360, 2021-2035. https://doi.org/10.1098/rstb.2005.1752.

Rousseeuw, P.J., 1987. Silhouettes: a graphical aid to the interpretation and validation of cluster analysis. J. Comput. Appl. Math. 20, 53-65. https://doi.org/10.1016/03770427(87)90125-7.

Salinger, M.J., Stigter, C.J., Das, H.P., 2000. Agrometeorological adaptation strategies to increasing climate variability and climate change. Agric. For. Meteorol. 103, 167-184. https://doi.org/10.1016/S0168-1923(00)00110-6.

Salley, S.W., Sleezer, R.O., Bergstrom, R.M., Martin, P.H., Kelly, E.F., 2016. A long-term analysis of the historical dry boundary for the great plains of North America: implications of climatic variability and climatic change on temporal and spatial patterns in soil moisture. Geoderma 274, 104-113. https://doi.org/10.1016/j.geoderma. 2016.03.020.

Salvatier, J., Wiecki, T., Fonnesbeck, C., 2015. Probabilistic programming in python using PyMC 1-24. 10.7717/peerj-cs.55.

Shao, H.B., Chu, L.Y., Jaleel, C.A., Manivannan, P., Panneerselvam, R., Shao, M.A., 2009. Understanding water deficit stress-induced changes in the basic metabolism of higher plants-biotechnologically and sustainably improving agriculture and the ecoenvironment in arid regions of the globe. Crit. Rev. Biotechnol. 29, 131-151. https://doi. org/10.1080/07388550902869792.

Steduto, P., Hsiao, T.C., Fereres, E., 2007. On the conservative behavior of biomass water productivity. Irrig. Sci. 25, 189-207. https://doi.org/10.1007/s00271-007-0064-1.

Troy, T.J., Kipgen, C., Pal, I., 2015. The impact of climate extremes and irrigation on US crop yields. Environ. Res. Lett. 10, 054013. https://doi.org/10.1088/1748-9326/10/ 5/054013.

Vicente-Serrano, S., Cuadrat-Prats, J.M., Romo, A., 2006. Early prediction of crop production using drought indices at different time-scales and remote sensing data: application in the Ebro Valley (north-east Spain). Int. J. Remote Sens. 27, 511-518. https://doi.org/10.1080/01431160500296032.

Vicente-Serrano, S.M., Beguería, S., López-Moreno, J.I., 2010. A multiscalar drought index sensitive to global warming: the standardized precipitation evapotranspiration index. J. Clim. 23, 1696-1718. https://doi.org/10.1175/2009JCLI2909.1.

Vicente-Serrano, S.M., Beguería, S., Lorenzo-Lacruz, J., Camarero, J.J., López-Moreno, J.I., Azorin-Molina, C., Revuelto, J., Morán-Tejeda, E., Sanchez-Lorenzo, A., 2012 Performance of drought indices for ecological, agricultural, and hydrological applications. Earth Interact. 16, 1-27. https://doi.org/10.1175/2012EI000434.1.

Vicente-Serrano, S.M., Gouveia, C., Camarero, J.J., Begueria, S., Trigo, R., Lopez-Moreno, J.I., Azorin-Molina, C., Pasho, E., Lorenzo-Lacruz, J., Revuelto, J., Moran-Tejeda, E., Sanchez-Lorenzo, A., 2013. Response of vegetation to drought time-scales across global land biomes. Proc. Natl. Acad. Sci. 110, 52-57. https://doi.org/10.1073/pnas. 1207068110 .

Vicente-Serrano, S.M., Miralles, D.G., Domínguez-Castro, F., Azorin-Molina, C., El Kenawy, A., Mcvicar, T.R., Tomás-Burguera, M., Beguería, S., Maneta, M., PeñaGallardo, M., 2018. Global assessment of the standardized evapotranspiration deficit index (SEDI) for drought analysis and monitoring. J. Clim. 31, 5371-5393. https:// doi.org/10.1175/JCLI-D-17-0775.1.

Wang, Q., Wu, J., Lei, T., He, B., Wu, Z., Liu, M., Mo, X., Geng, G., Li, X., Zhou, H., Liu, D., 2014. Temporal-spatial characteristics of severe drought events and their impact on agriculture on a global scale. Quat. Int. 349, 10-21. https://doi.org/10.1016/j. quaint.2014.06.021.

Yamoah, C.F., Walters, D.T., Shapiro, C.A., Francis, C.A., Hayes, M.J., 2000. Standardized precipitation index and nitrogen rate effects on crop yields and risk distribution in maize. Agric. Ecosyst. Environ. 80, 113-120. https://doi.org/10.1016/S01678809(00)00140-7.

Zipper, S.C., Qiu, J., Kucharik, C.J., 2016. Drought effects on US maize and soybean production: spatiotemporal patterns and historical changes. Environ. Res. Lett. 11, 094021. https://doi.org/10.1088/1748-9326/11/9/094021. 